Pacific Journal of Mathematics

AN ARITHMETIC POISSON FORMULA 


\title{
AN ARITHMETIC POISSON FORMULA
}

\author{
BRUCE C. BERNDT
}

Let $a(n)$ denote any arithmetic function. Since most arithmetic functions that are encountered are defined on only the nonnegative integers, we define $a(-n)=a(n)$ for each positive integer $n$. Our objective is to develop a Poisson type formula for $\sum_{n=-\infty}^{\infty} a(n) f(n)$, where $f$ belongs to a suitable class of functions. We conclude the paper with several applications of our arithmetic Poisson formula.

In another paper [2], the author has used a new technique in contour integration to examine infinite series of the type $\sum_{n=0}^{\infty} a(n) f(n)$, where now $f$ is a suitable rational function. The author's method has been generalized and improved by Krishnaiah and Sita Rama Chandra Rao [5].

Let $b(n)$ be an arithmetic function, and let $S$ denote any subset of the natural numbers. Define, for each positive integer $m$,

$$
a(m, n ; S)=\sum_{\substack{d \leq m \\ d \mid n \\ d \in S}} b(d) \text { and } a(n ; S)=\sum_{\substack{d \mid n \\ d \in S}} b(d) .
$$

Clearly, if $m \geqq n, a(m, n ; S)=a(n ; S)$. If $S$ is the set of all positive integers, we write $a(n ; S)=a(n)$. Alternatively, given an arithmetic function $a(n)$, we could define $b(n)$ by

$$
b(n)=\sum_{d \mid n} \mu(d) a(n / d),
$$

where $\mu$ denotes the Möbius function.

There exist several formulations of Poisson's summation formula

$$
\sum_{n=-\infty}^{\infty} f(n)=\sum_{n=-\infty}^{\infty} \int_{-\infty}^{\infty} f(x) e^{2 \pi i n x} d x
$$

in the literature, where here and in the sequel all doubley infinite sums are interpreted symmetrically, i.e., as $\lim _{N \rightarrow \infty} \sum_{n=-N}^{N}$. We shall choose the setting (with slightly stronger hypotheses) from Bellman's book [1, p. 8]. Thus, let $f(x)$ be continuous on $(-\infty, \infty)$, suppose that $f \in L^{1}(-\infty, \infty)$, and assume that the left and right sides of (2) converge absolutely. Then (2) holds.

THeorem. Suppose that $f$ satisfies the conditions of Poisson's formula (2) as specified above. Let $a(n)$ and $b(n)$ denote arithmetic functions as related above. Assume also that $\sum_{n=-\infty}^{\infty} a(n) f(n)$ is absolutely convergent. Then 


$$
\sum_{\substack{n=-\infty \\ n \neq 0}}^{\infty} a(n ; S) f(n)=\sum_{\substack{d=1 \\ d \in S}}^{\infty} \frac{b(d)}{d}\left\{\sum_{r=-\infty}^{\infty} \int_{-\infty}^{\infty} f(x) e^{2 \pi i r x / d} d x-f(0) d\right\}
$$

Proof. For each natural number $d$ and real number $x$, define

$$
\mathscr{S}(d ; x)=\sum_{j=0}^{d-1} e^{2 \pi i j x / d} .
$$

Thus, if $n$ is an integer,

$$
\mathscr{S}(d ; n)= \begin{cases}d, & \text { if } d \mid n, \\ 0, & \text { otherwise } .\end{cases}
$$

Define, for each natural number $m$,

$$
B_{m}(x ; S)=\sum_{\substack{d=1 \\ d \in S}}^{m} \frac{b(d)}{d} \mathscr{S}(d ; x) .
$$

Hence, by (1) and (4), if $n \neq 0$,

$$
B_{m}(n ; S)=a(m, n ; S),
$$

while if $n=0$,

$$
B_{m}(0 ; S)=\sum_{\substack{d=1 \\ d \in S}}^{m} b(d)
$$

Now put $F(x)=B_{m}(x ; S) f(x)$. From the hypotheses of our theorem, it is easily seen that the real and imaginary parts of $F(x)$ satisfy the conditions of the ordinary Poisson summation formula (2). Hence, using (5) and (6), we find that

$$
\begin{aligned}
\sum_{\substack{n=-\infty \\
n \neq 0}}^{\infty} a(m, n ; S) f(n)+\sum_{\substack{d=1 \\
d \in S}}^{m} b(d) f(0) \\
=\sum_{n=-\infty}^{\infty} \int_{-\infty}^{\infty} f(x) \sum_{\substack{d=1 \\
d \in S}}^{m} \frac{b(d)}{d} \sum_{j=0}^{d-1} e^{2 \pi i(n+j / d) x} d x .
\end{aligned}
$$

Setting $r=n d+j$, we find that

$$
\sum_{\substack{n=-\infty \\ n \neq 0}}^{\infty} a(m, n ; S) f(n)=\sum_{\substack{d=1 \\ d \in S}}^{m} \frac{b(d)}{d}\left\{\sum_{r=-\infty}^{\infty} \int_{-\infty}^{\infty} f(x) e^{2 \pi i r x / d} d x-f(0) d\right\} .
$$

Letting $m$ tend to $\infty$ on both sides above, we deduce (3). Taking the limit under the summation sign on the left side is justified by a lemma of Krishnaiah and Sita Rama Chandra Rao [5] that requires the absolute convergence of $\sum_{n=-\infty}^{\infty} a(n) f(n)$.

In each of the examples below we tacitly assume that $a(n)$ and $b(n)$ satisfy the hypotheses of our theorem. 
EXAMPLE 1. Let $f(x)=1 /\left(x^{2}+a^{2}\right)$, where $a^{2} \neq n^{2}$ if $n$ is an integer. Now if $r$ is any integer [4, p. 406],

$$
\int_{-\infty}^{\infty} \frac{e^{2 \pi i r x / d}}{x^{2}+a^{2}} d x=\frac{\pi}{2} e^{-2 \pi r a / d}
$$

After an elementary computation, the theorem yields

$$
\sum_{n=1}^{\infty} \frac{a(n ; S)}{n^{2}+a^{2}}=\frac{1}{2 a^{2}} \sum_{\substack{d=1 \\ d \in S}}^{\infty} b(d)\left\{\frac{\pi a}{d} \operatorname{coth}\left(\frac{\pi a}{d}\right)-1\right\} .
$$

For some specific examples of the above formula, see [2] and [5].

A formula for $\sum_{n=1}^{\infty}(-1)^{n} a(n ; S) /\left(n^{2}+a^{2}\right)$ may be obtained by setting $f(x)=\cos (\pi x) /\left(x^{2}+a^{2}\right)$ in the theorem. See [5] for such a formula.

EXAMPLE 2. Let $f(x)=x^{2} /\left(x^{4}+a^{4}\right)$, where $a^{4} \neq-n^{4}$ if $n$ is an integer. Then for any integer $r$ [4, pp. 409, 42],

$$
\begin{aligned}
& \sum_{r=1}^{\infty} \int_{0}^{\infty} \frac{x^{2} \cos (2 \pi r x / d)}{x^{4}+a^{4}} d x \\
&=\frac{\pi \sqrt{2}}{4 a} \sum_{r=1}^{\infty} e^{-\sqrt{2} \pi r a / d}\{\cos (\sqrt{2} \pi r a / d)-\sin (\sqrt{2} \pi r a / d)\} \\
&=\frac{\pi \sqrt{2}}{8 a}\left\{\frac{\sinh (\sqrt{2} \pi a / d)}{\cosh (\sqrt{2} \pi a / d)-\cos (\sqrt{2} \pi a / d)}\right. \\
&\left.-1-\frac{\sin (\sqrt{2} \pi a / d)}{\cosh (\sqrt{2} \pi a / d)-\cos (\sqrt{2} \pi a / d)}\right\}
\end{aligned}
$$

Hence, using also the integral evaluation for $r=0$, we deduce that

$$
\sum_{n=1}^{\infty} \frac{a(n ; S) n^{2}}{n^{4}+a^{4}}=\frac{\pi \sqrt{2}}{4 a} \sum_{\substack{d=1 \\ d \in S}}^{\infty} \frac{b(d)}{d}\left\{\frac{\sinh (\sqrt{2} \pi a / d)-\sin (\sqrt{2} \pi a / d)}{\cosh (\sqrt{2} \pi a / d)-\cos (\sqrt{2} \pi a / d)}\right\} .
$$

In particular, if we let $a(n)=1, n=1$, and $a(n)=0, n>1$, then $b(n)=\mu(n)$, and so

$$
\frac{1}{1+a^{4}}=\frac{\pi \sqrt{2}}{4 a} \sum_{d=1}^{\infty} \frac{\mu(d)}{d}\left\{\frac{\sinh (\sqrt{2} \pi a / d)-\sin (\sqrt{2} \pi a / d)}{\cosh (\sqrt{2} \pi a / d)-\cos (\sqrt{2} \pi a / d)}\right\} .
$$

EXAMPLE 3. Let $f(x)=\operatorname{sech}(\pi x)$. Then for each integer $r[4$, p. 503],

$$
\int_{-\infty}^{\infty} \frac{\cos (2 \pi r x / d)}{\cosh (\pi x)} d x=\operatorname{sech}(\pi r / d)
$$

Hence, 


$$
\sum_{n=1}^{\infty} a(n ; S) \operatorname{sech}(\pi n)=\frac{1}{2} \sum_{\substack{d=1 \\ d \in S}}^{\infty} \frac{b(d)}{d}\left\{2 \sum_{r=1}^{\infty} \operatorname{sech}(\pi r / d)+1-d\right\} .
$$

As an example, let $b(n)$ be Ramanujan's trigonometric sum $c_{n}(m)$, the sum of the $m$ th powers of the primitive $n$th roots of unity. Then $a(n)=n$ or 0 according as $n \mid m$ or $n \nmid m$. Then the above formula yields

$$
\sum_{n \mid m} n \operatorname{sech}(\pi n)=\frac{1}{2} \sum_{d=1}^{\infty} \frac{c_{d}(m)}{d}\left\{2 \sum_{r=1}^{\infty} \operatorname{sech}(\pi r / d)-d\right\},
$$

since $\sum_{d=1}^{\infty} c_{d}(m) / d=0$.

EXAMPLE 4. Let $f(x)=x \operatorname{csch}(\pi x)$. Then if $r$ is any integer $[4$, p. 511],

$$
\int_{0}^{\infty} \frac{x \cos (2 \pi r x / d)}{\sinh (\pi x)} d x=\frac{1}{4} \operatorname{sech}^{2}(\pi r / d)
$$

Hence, our theorem gives

$$
\sum_{n=1}^{\infty} a(n ; S) n \operatorname{csch}(\pi n)=\sum_{\substack{d=1 \\ d \in S}}^{\infty} \frac{b(d)}{d}\left\{\frac{1}{2} \sum_{r=1}^{\infty} \operatorname{sech}^{2}(\pi r / d)+\frac{1}{4}-\frac{d}{2 \pi}\right\} .
$$

In particular, if we let $a(n)=\sigma_{-1}(n)=\sum_{d \mid n} 1 / d$, the above formula reduces to

$$
\sum_{n=1}^{\infty} \sigma_{1}(n) \operatorname{csch}(\pi n)=\frac{\pi^{2}}{24}+\frac{1}{2} \sum_{d=1}^{\infty} \frac{1}{d^{2}}\left\{\sum_{r=1}^{\infty} \operatorname{sech}^{2}(\pi r / d)-\frac{d}{\pi}\right\} .
$$

EXAMPLE 5. Let $f(t)=(x /|t|)^{1 / 2} J_{1}(2 \pi \sqrt{|t| x}), x>0$, where $J_{k}$ denotes the ordinary Bessel function of order $k$. From the definition of $J_{1}$ it is easily seen that $f(0)=\pi x$. Since $J_{0}^{\prime}(u)=-J_{1}(u)$, we find that

$$
\int_{0}^{\infty}(x / t)^{1 / 2} J_{1}(2 \pi \sqrt{t x}) d t=\frac{1}{\pi} \int_{0}^{\infty} J_{1}(u) d u=\frac{1}{\pi} .
$$

Next, for each nonzero integer $r,[4, p .742]$,

$$
\begin{aligned}
& \int_{0}^{\infty}(x / t)^{1 / 2} J_{1}(2 \pi \sqrt{t x}) \cos (2 \pi r t / d) d t \\
& \quad=\frac{1}{\pi} \int_{0}^{\infty} J_{1}(u) \cos \left(\frac{r u^{2}}{2 \pi x d}\right) d u=\frac{2}{\pi} \sin ^{2}\left(\frac{\pi x d}{4 r}\right) .
\end{aligned}
$$

Put $a(n)=r(n)$, the number of representations of $n$ as the sum of two squares. Then $r(n)=4 \sum_{d \mid n} \chi(d)$, where $\chi$ denotes the primitive character of modulus 4 . Thus, the theorem yields 


$$
\begin{aligned}
& \sum_{n=1}^{\infty} r(n)(x / n)^{1 / 2} J_{1}(2 \pi \sqrt{n x}) \\
& =4 \sum_{d=1}^{\infty} \frac{\chi(d)}{d}\left\{\frac{4}{\pi} \sum_{r=1}^{\infty} \sin ^{2}\left(\frac{\pi x d}{4 r}\right)+\frac{1}{\pi}-\frac{\pi x d}{2}\right\} .
\end{aligned}
$$

Now Voronoï [6] has shown that

$$
\sum_{n \leqq x}^{\prime} r(n)=\pi x-1+\sum_{n=1}^{\infty} r(n)(x / n)^{1 / 2} J_{1}(2 \pi \sqrt{n x}),
$$

where the dash' on the summation sign on the left side indicates that if $x$ is an integer, only $r(x) / 2$ is counted. Combining the last two equalities and using the fact that

$$
\sum_{a=1}^{\infty} \chi(d) / d=\pi / 4
$$

we deduce that

$$
\sum_{n \leqq x}^{\prime} r(n)=\pi x+4 \sum_{d=1}^{\infty} \frac{\chi(d)}{d}\left\{\frac{4}{\pi} \sum_{r=1}^{\infty} \sin ^{2}\left(\frac{\pi x d}{4 r}\right)-\frac{\pi x d}{2}\right\} .
$$

Unfortunately, this does not appear to be of any use in the "circle problem." For related material, see $[3, \S 8]$ and the references contained therein.

For additional examples, see [2] and, especially, [5].

\section{REFERENCES}

1. R. Bellman, A Brief Introduction to Theta Functions, Holt, Rinehart and Winston, New York, 1961.

2. B. C. Berndt, $A$ new method in arithmetical functions and contour integration, Canad. Math. Bull., 16 (1973), 381-388.

3. — Periodic Bernoulli numbers, summation formulas and applications, Theory and Application of Special Functions, Richard A. Askey, ed., Academic Press, New York, 1975, pp. 143-189.

4. I. S. Gradshteyn and I. M. Ryzhik, Table of Integrals, Series, and Products, Academic Press, New York, 1965.

5. P. V. Krishnaiah and R. Sita Rama Chandra Rao, On Berndt's method in arithmetical functions and contour integration, Canad. Math. Bull., 22 (1979), 177-185.

6. M. G. Voronoï, Sur la développement, à l'aide des fonctions cylindriques, des sommes doubles $\sum f\left(p m^{2}+2 q m n+r n^{2}\right)$, où $p m^{2}+2 q m n+r n^{2}$ est une forme positive à coefficients entiers, Verhandlungen des dritten Internat, Math.-Kongr. Heidelberg, Teubner Leipzig, 1905, pp. 241-245.

Received July 13, 1978.

UNIVERSITY OF ILLINOIS

URBANA, IL 61801 



\title{
PACIFIC JOURNAL OF MATHEMATICS
}

\section{EDITORS}

\author{
DONALD BABBITT (Managing Editor) \\ University of California \\ Los Angeles, CA 90024 \\ Hugo Rossi \\ University of Utah \\ Salt Lake City, UT 84112 \\ C. C. MOORE and ARthur Agus \\ University of California \\ Berkeley, CA 94720
}

J. DUGUNDJI

Department of Mathematics

University of Southern California

Los Angeles, CA 90007

R. FINN and J. MILGRAM

Stanford University

Stanford, CA 94305

\section{ASSOCIATE EDITORS}
R. ARENS
E. F. BeCKENBACH
B. H. NeumanN
F. WoLF
K. YoSHIDA

\section{SUPPORTING INSTITUTIONS}

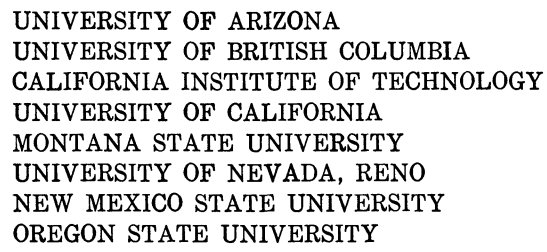

UNIVERSITY OF ARIZONA

UNIVERSITY OF BRITISH COLUMBIA

CALIFORNIA INSTITUTE OF TECHNOLOGY

UNIVERSITY OF CALIFORNIA

MONTANA STATE UNIVERSITY

UNIVERSITY OF NEVADA, RENO

NEW MEXICO STATE UNIVERSITY

OREGON STATE UNIVERSITY

\author{
UNIVERSITY OF OREGON \\ UNIVERSITY OF SOUTHERN CALIFORNIA \\ STANFORD UNIVERSITY \\ UNIVERSITY OF AAWAII \\ UNIVERSITY OF TOKYO \\ UNIVERSITY OF UTAH \\ WASHINGTON STATE UNIVERSITY \\ UNIVERSITY OF WASHINGTON
}

The Supporting Institutions listed above contribute to the cost of publication of this Journal, but they are not owners or publishers and have no responsibility for its content or policies,

Mathematical parers intended for publication in the Pacific Journal of Mathematics should be in typed form or offset-reproduced, (not dittoed), double spaced with large margins. Please do not use built up fractions in the text of the manuscript. However, you may use them in the displayed equations. Underline Greek letters in red, German in green, and script in blue. The first paragraph or two must be capable of being used separately as a synopsis of the entire paper. Please propose a heading for the odd unmbered pages of less than 35 characters. Manuscripts, in triplicate, may be sent to any one of the editors. Please classify according to the scheme of Math. Reviews, Index to Vol. 39. Supply name and address of author to whom proofs should be sent. All other communications should be addressed to the managing editor, or Elaine Barth, University of California, Los Angeles, California, 90024.

50 reprints to each author are provided free for each article, only if page charges have been substantially paid. Additional copies may be obtained at cost in multiples of 50 .

The Pacific Journal of Mathematics is issued monthly as of January 1966, Regular subscription rate: $\$ 114.00$ a year (6 Vol., 12 issues). Special rate: $\$ 57.00$ a year to individual members of supporting institution.

Subscriptions, orders for numbers issued in the last three calendar years, and changes of address shoud be sent to Pacific Journal of Mathematics, P.O. Box 969, Carmel Valley, CA 93924, U.S.A. Old back numbers obtainable from Kraus Periodicals Co., Route 100, Millwood, NY 10546.

PUBLISHED BY PACIFIC JOURNAL OF MATHEMATICS, A NON-PROFIT CORPORATION

Printed at Kokusai Bunken Insatsusha (International Academic Printing Co., Ltd.). 8-8, 3-chome, Takadanobaba, Shinjuku-ku, Tokyo 160, Japan. 


\section{Pacific Journal of Mathematics}

\section{Vol. 103, No. $2 \quad$ April, 1982}

Alberto Alesina and Leonede De Michele, A dichotomy for a class of positive

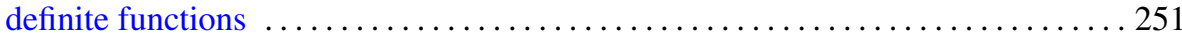

Kahtan Alzubaidy, Rank 2 -groups, $p>3$, and Chern classes . . . . . . . . . . 259

James Arney and Edward A. Bender, Random mappings with constraints on

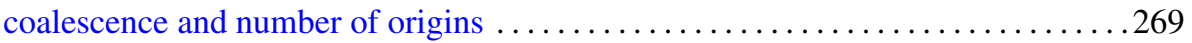

Bruce C. Berndt, An arithmetic Poisson formula . . . . . . . . . . . . . . . 295

Julius Rubin Blum and J. I. Reich, Pointwise ergodic theorems in 1.c.a. groups . . . 301

Jonathan Borwein, A note on $\varepsilon$-subgradients and maximal monotonicity . . . . . . . 307

Andrew Michael Brunner, Edward James Mayland, Jr. and Jonathan Simon,

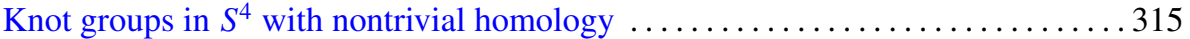

Luis A. Caffarelli, Avner Friedman and Alessandro Torelli, The two-obstacle

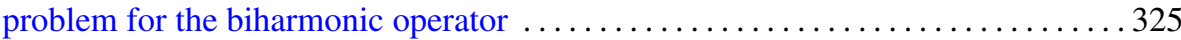

Aleksander Całka, On local isometries of finitely compact metric spaces . . . . . . 337

William S. Cohn, Carleson measures for functions orthogonal to invariant

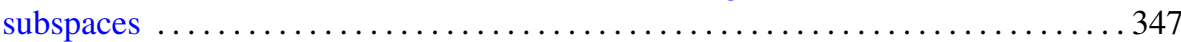

Roger Fenn and Denis Karmen Sjerve, Duality and cohomology for one-relator

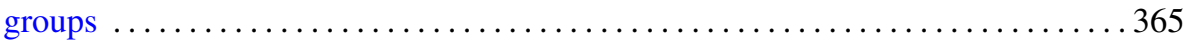

Gen Hua Shi, On the least number of fixed points for infinite complexes . . . . . . . 377

George Golightly, Shadow and inverse-shadow inner products for a class of linear

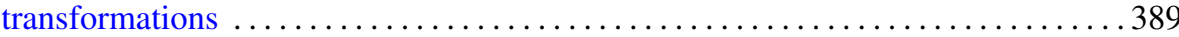

Joachim Georg Hartung, An extension of Sion's minimax theorem with an

application to a method for constrained games $\ldots \ldots \ldots \ldots \ldots \ldots \ldots \ldots \ldots \ldots . \ldots 4$

Vikram Jha and Michael Joseph Kallaher, On the Lorimer-Rahilly and

Johnson-Walker translation planes

Kenneth Richard Johnson, Unitary analogs of generalized Ramanujan sums .

Peter Dexter Johnson, Jr. and R. N. Mohapatra, Best possible results in a class of inequalities

Dieter Jungnickel and Sharad S. Sane, On extensions of nets

Johan Henricus Bernardus Kemperman and Morris Skibinsky, On the

characterization of an interesting property of the arcsin distribution ...

Karl Andrew Kosler, On hereditary rings and Noetherian $V$-rings

William A. Lampe, Congruence lattices of algebras of fixed similarity type. II . . . . 475

M. N. Mishra, N. N. Nayak and Swadeenananda Pattanayak, Strong result for real zeros of random polynomials

Sidney Allen Morris and Peter Robert Nickolas, Locally invariant topologies on free groups

Richard Cole Penney, A Fourier transform theorem on nilmanifolds and nil-theta functions

Andrei Shkalikov, Estimates of meromorphic functions and summability theorems

László Székelyhidi, Note on exponential polynomials

William Thomas Watkins, Homeomorphic classification of certain inverse limit spaces with open bonding maps $\ldots \ldots \ldots \ldots \ldots \ldots \ldots \ldots$

David G. Wright, Countable decompositions of $E^{n}$

Takayuki Kawada, Correction to: "Sample functions of Pólya processes" .

Z. A. Chanturia, Errata: "On the absolute convergence of Fourier series of the 